\title{
Iliac Crest
}

National Cancer Institute

\section{Source}

National Cancer Institute. Iliac Crest. NCI Thesaurus. Code C103818.

The thick curved ridge in the upper area of the ilium. 